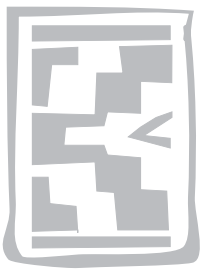

\title{
Seasonal prevalence of bovine trypanosomosis in a tsetse-infested zone and a tsetse-free zone of the Amhara Region, north-west Ethiopia
}

\author{
T. CHERENET, R.A. SANI ${ }^{1}$, J.M. PANANDAM ${ }^{2}$, S. NADZR ${ }^{1}$, N. SPEYBROECK ${ }^{3}$ \\ and P. VAN DEN BOSSCHE ${ }^{3,4, *}$
}

\begin{abstract}
CHERENET, T., SANI, R.A., PANANDAM, J.M., NADZR, S., SPEYBROECK, N. \& VAN DEN BOSSCHE, P. 2004. Seasonal prevalence of bovine trypanosomosis in a tsetse-infested zone and a tsetse-free zone of the Amhara Region, north-west Ethiopia. Onderstepoort Journal of Veterinary Research, 71:307-312

During a period of four consecutive years, trypanosomosis surveys were conducted in a tsetseinfested and tsetse-free area of the Amhara Region of north-west Ethiopia. In each study area randomly selected communal cattle were sampled and their blood was investigated using parasitological diagnostic methods. At the same time the population of biting flies was sampled. The monthly average prevalence of trypanosome infections in cattle did not differ significantly between study areas. In both study areas, the prevalence of trypanosome infections was highest during the long rainy season. Trypanosome infections were mainly due to Trypanosoma vivax and they significantly reduced the average packed cell volume and the body condition of the animals. The monthly prevalence of infection was correlated with the density of biting flies, such as Tabanidae and Stomoxys spp., in the preceding month suggesting an important role of mechanical transmission in the epidemiology of trypanosomosis in both areas.
\end{abstract}

Keywords: Biting flies, bovine trypanosomosis, epidemiology, Ethiopia, prevalence

\section{INTRODUCTION}

Bovine trypanosomosis is a serious constraint to agricultural production in extensive areas of the tsetse-infested Ethiopian lowlands (Slingenbergh 1972). Tsetse flies are found mainly in the southern

\footnotetext{
* Author to whom correspondence should be addressed

1 Faculty of Veterinary Medicine and ${ }^{2}$ Faculty of Agriculture, University Putra Malaysia, 43400 Serdang, Malaysia

3 Institute of Tropical Medicine, Veterinary Department, Nationalestraat 155, 2000 Antwerp, Belgium

4 Faculty of Veterinary Sciences, Department of Veterinary Tropical Diseases, Private Bag X04, Onderstepoort, 0110 South Africa
}

Accepted for publication 7 April 2004-Editor and western parts of the country (Langridge 1976). As a result of the trypanosomosis threat, a large proportion of the livestock population is found in the highlands that are assumed to be tsetse-free. Although livestock trypanosomosis is a well-known constraint to livestock production in Ethiopia little attention has been paid to the trypanosomosis situation in the Amhara Region in the north-western part of the country. Nevertheless, livestock are the backbone of the rural economy in this region where approximately one third of Ethiopia's cattle, sheep and goat population is found. To clarify the trypanosomosis situation a survey was conducted to determine not only the prevalence of trypanosome infections in cattle in a tsetse-infested area and a tsetse-free area of the Amhara Region but also the seasonal changes in the prevalence of the disease. 


\section{MATERIAL AND METHODS}

\section{Study areas}

The study areas were located in the Amhara Region of north-west Ethiopia. The region covers an area of approximately $170000 \mathrm{~km}^{2}$ and is divided into 11 administrative zones. It is characterized by high plateaux, mountains and broad valleys. The elevation varies from about $700-4600 \mathrm{~m}$ above sea level. The steep terrain characterising much of the mountainous areas limits agricultural development. The altitude of the study areas ranges from 700-2 $500 \mathrm{~m}$ above sea level.

The climate in the study areas can be divided into a short rainy season or "belg" between late February and early May and a longer, more reliable rainy season or "kiremt" from June to October.

The study areas are densely populated with an estimated average human population density of about 100 persons per $\mathrm{km}^{2}$. More than $90 \%$ of the population live in rural areas and practice subsistence, rainfed cropping combined with extensive grazing of livestock. Approximately $30 \%$ of the land area is cultivated, $12 \%$ is used for grazing, $19 \%$ is forest and bush, $26 \%$ is unproductive land and $13 \%$ is classified as un-utilizable land (BoPED 2000).

Part of the Amhara Region is tsetse-infested. Glossina morsitans submorsitans and Glossina tachinoides are present (Langridge 1976). Three tsetseinfested administrative zones, West Gojjam, East Gojjam and Awi, were included in this study. Samples were collected from cattle from the Guanga, Ankesha, Dangla, Bure and Denbecha districts in this zone which are located on the edge of the tsetsebelt. The two tsetse-free study areas are located in the North and South Gonder administrative zones. Cattle were sampled in the Gonder-Zuria, Fogera, Libo-kemekem, Este, Chellga, Metema and Bassoliben districts. The tsetse-free study areas are located about $500 \mathrm{~km}$ north of the tsetse-belt of the Amhara Region at an altitude above $1800 \mathrm{~m}$.

Chemotherapy is the only trypanosomosis control method used in the study areas. Veterinary supervision is inadequate, which may lead to the inappropriate use of drugs or use of drugs of substandard quality.

\section{Sample selection}

The cattle in the tsetse-free and tsetse-infested study areas are indigenous zebus (Fogera breed). The surveys were conducted between 1997 and 2001. Ten villages were identified in each district and vis- ited at 4 month intervals each year. During each sampling, about 40 heads of communal cattle were selected in each village using a multistage random sampling technique (Putt, Shaw, Woods, Tyler \& James 1988).

\section{Sampling method}

The parasitological diagnostic tests used were those described by Paris, Murray \& McOdimba (1982). Blood was collected from an ear vein into heparinized microhaematocrit centrifuge capillary tubes and onto glass slides in order to make thick and thin blood smears. The capillary tubes were sealed with "Cristaseal" (Hawksley) and centrifuged immediately in a microhaematocrit centrifuge for $5 \mathrm{~min}$ at 9000 rpm. After centrifugation, the packed cell volume (PCV) was determined. Animals with a PCV $\leq 24 \%$ were considered to be anaemic. The buffy coat and the uppermost layer of red blood cells in each specimen were extracted, placed onto a microscope slide and examined under a phase contrast microscope with a $\times 40$ objective lens for the presence of motile trypanosomes. The thick and thin blood smears were stained with Giemsa and examined under a light microscope using a $\times 100$ oil immersion objective lens.

At the time of sampling, the owner, age and sex of each animal were recorded and its body condition was scored using the method described by Nicholson \& Butterworth (1986).

\section{Entomological survey}

The population of biting flies was monitored using unbaited biconical (Challier, Eyraud, Lafaye \& Laveissière 1977) and NGU traps (Brightwell, Dransfield, Kyorku, Golder, Tarimo \& Munga 1987). Three traps were deployed in representative habitats in the tsetse-infested and tsetse-free study sites for 5 days each month. Records were kept of the fly species and number and sex of each species captured in each trap during each month. The monthly mean index of apparent abundance (IAA) of biting flies in the two study sites was calculated as the mean number of biting flies (males and females) captured per trap per month.

\section{Statistical analyses}

Statistical analyses were carried out in Stata 7 (StataCorp. 2001). Use was made of logistic regression and regression analysis. The relationship between the prevalence of trypanosome infection and the IAA of biting flies was determined after arc- 
sine transformation. The PCV data were compared using the non-parametric Kruskal-Wallis equality of population rank test.

\section{RESULTS}

Between May 1997 and December 2001, a total of 7079 head of cattle (3888 in the tsetse-free area and 3191 in the tsetse-infested study area) were sampled. A total of 501 animals (262 in the tsetsefree area and 239 in the tsetse-infested area) were found to be infected with trypanosomes. The average parasitological prevalence was $6.6 \%$ and $7.3 \%$ in the tsetse-free and tsetse-infested study area, respectively. The parasitological prevalence of trypanosomosis differed significantly between months $(P<0.0001)$ but did not differ between the tsetse- free study area and the tsetse-infested study area $(P=0.57)$. Differences between years were small and data were pooled for further analyses. The parasitological prevalence was highest during the long rainy season (June to October) (Fig. 1).

The majority of the infected animals (262 or $100 \%$ in the tsetse-free and 223 or $93.3 \%$ in the tsetseinfested area) was infected with Trypanosoma vivax. A total of 450 animals were infected only with $T$. vivax and the remainder were co-infected with either Trypanosoma congolense (29) or Trypanosoma brucei (6) (Table 1). Trypanosoma brucei was not detected in the tsetse-free area (Table 1). Trypanosoma congolense accounted for $4.2 \%$ of the trypanosome infections in the tsetse-free area and $10.0 \%$ of the trypanosome infections in the tsetseinfested area (Table 1).

TABLE 1 Monthly total number of cattle with T. vivax, T. congolense, T. brucei or mixed infection in the tsetse-free study area and tsetse-infested study area of the Amhara Region of Ethiopia

\begin{tabular}{|c|c|c|c|c|c|c|c|c|c|c|}
\hline \multirow{2}{*}{ Month } & \multicolumn{2}{|c|}{ T. vivax } & \multicolumn{2}{|c|}{ T. congolense } & \multicolumn{2}{|c|}{ T. brucei } & \multicolumn{2}{|c|}{ Mixed T.c./T.v. } & \multicolumn{2}{|c|}{ Mixed T.b./T.v. } \\
\hline & Free & Infested & Free & Infested & Free & Infested & Free & Infested & Free & Infested \\
\hline Jan & 28 & 19 & & & & 1 & & 1 & & 1 \\
\hline Feb & 26 & 10 & & & & & & & & \\
\hline Mar & 18 & 20 & & & & & & & & \\
\hline Apr & 36 & 5 & & & & & & & & \\
\hline May & 16 & 7 & & & & & & & & \\
\hline Jun & 21 & 30 & & & & 1 & & & & \\
\hline Jul & 11 & 7 & & & & & & & & 1 \\
\hline Aug & 1 & 6 & & & & 1 & & & & \\
\hline Sep & 22 & 32 & & & & 1 & 11 & 11 & & 2 \\
\hline Oct & 16 & 26 & & & & 4 & & 4 & & 1 \\
\hline Nov & 30 & 24 & & 6 & & & & 1 & & \\
\hline Dec & 26 & 13 & & 1 & & 1 & & 1 & & 1 \\
\hline
\end{tabular}

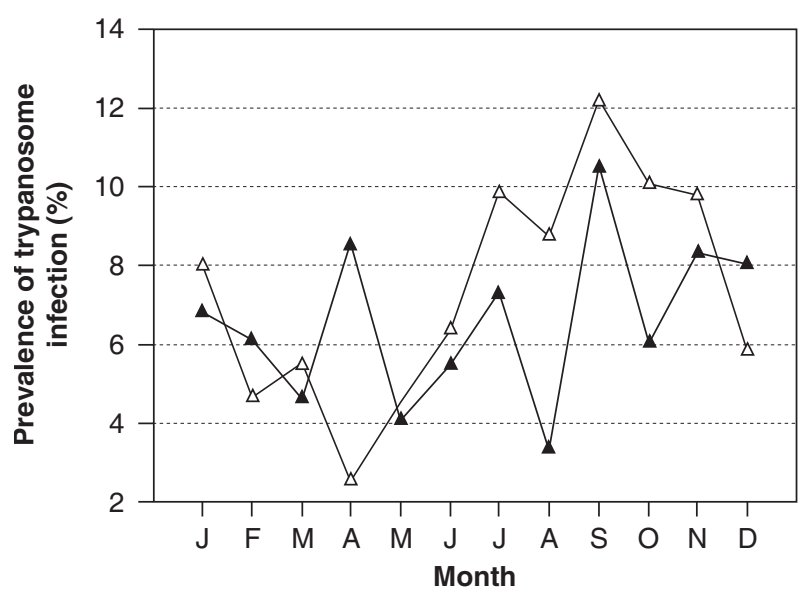

FIG. 1 Monthly average prevalence of trypanosome infections in cattle in the tsetse-infested $(\triangle)$ study area and tsetse-free ( $\mathbf{\Delta})$ study area of the Amhara Region of north western Ethiopia

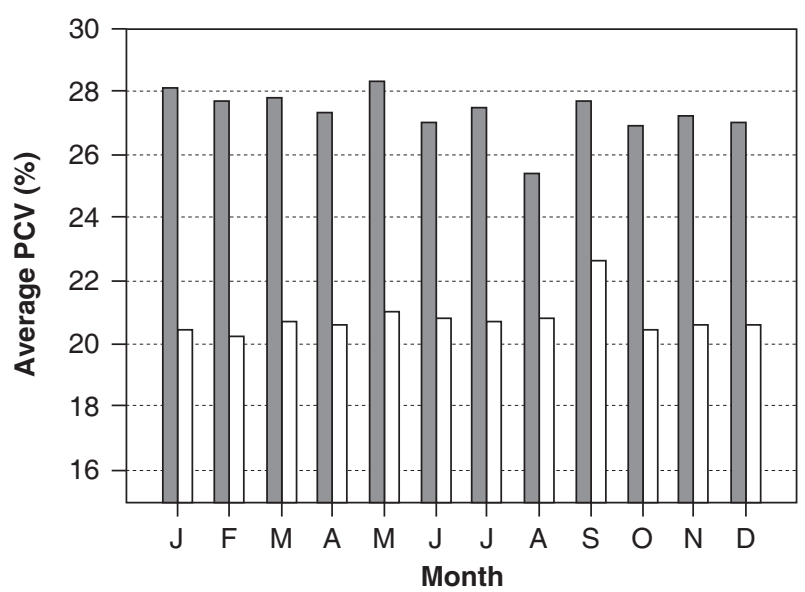

FIG. 2 Monthly average PCV of parasitologically positive ( $\square$ ) and negative ( $\square$ ) cattle 


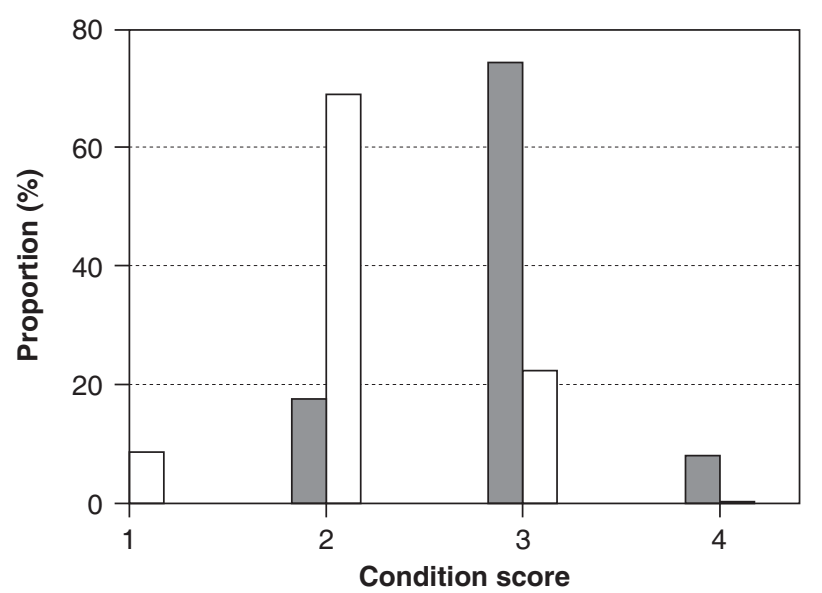

FIG. 3 Proportion of the total number of cattle, infected ( $\square$ ) or not-infected $(\square)$ with trypanosomes, belonging to different body condition scoring categories

The prevalence of trypanosome infections did not differ between age categories $(P=0.77)$ or sexes $(P=0.09)$. The average PCV of the animals infected with trypanosomes was $21.1 \pm 3.4 \%$ and $20.9 \pm$ $2.5 \%$ in the tsetse-free area and tsetse-infested study area, respectively. It was significantly lower $(P=0.001)$ than the average PCV of the animals that were parasitologically negative $(28.1 \pm 5.2 \%$ and $26.9 \pm 5.2 \%$ for the tsetse-free area and tsetseinfested study area, respectively) (Fig. 2).

The body condition score of cattle infected with trypanosomes was significantly lower $(P=0.012)$ than that of the parasitologically negative animals (Fig. 3 ).

Throughout the entomological surveillance period, no tsetse flies were captured in the tsetse-free area. Glossina m. submorsitans and G. tachinoides were present in the tsetse-infested areas. Haematopota maculosifacies, Hippobosca maculata, Stomoxys calcitrans, Chrysops streptobalius and Tabanus atrimanus were biting flies captured in both the tsetsefree area and the tsetse-infested area. The IAA of biting flies (including tsetse flies) showed a clear seasonal trend with high IAA during the long rainy season (Fig. 4). The monthly IAA of biting flies correlated significantly $(P=0.023)$ with the prevalence of trypanosome infections in the same month.

\section{DISCUSSION}

The results suggest that trypanosomosis is an important disease of cattle in the Amhara Region of north-west Ethiopia. Taking into account the low sensitivity of the parasitological diagnostic methods
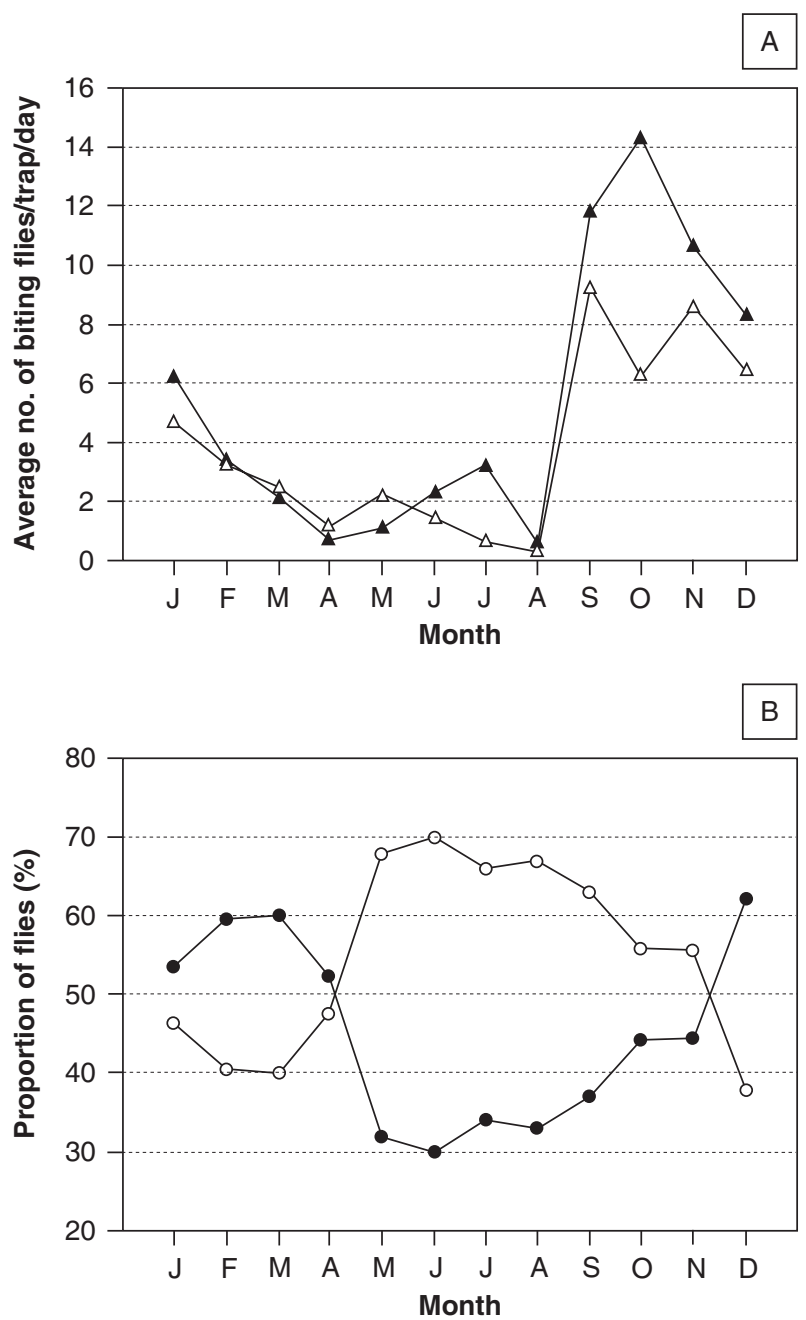

FIG. 4 Monthly average index of apparent abundance of biting flies in the tsetse-free $(\boldsymbol{\Delta})$ study area and tsetseinfested $(\triangle)$ study area $(A)$ and monthly proportion of tsetse flies $(\bullet)$ and other biting flies $(0)$ in captures in the tsetse-infested study areas (B)

and the uncontrolled use of trypanocidal drugs, the real prevalence of infection is probably substantially higher. The average overall prevalence of infection in the tsetse-infested study area was comparable to the overall prevalence of infection in the tsetse-free study area but lower than the prevalences reported from other tsetse-infested regions in Ethiopia (Abebe \& Jobre 1996; Kidanemariam, Hadgu \& Sahle 2002). This is attributed to the location of our sampling sites. Sampling was conducted on the edge of the tsetsebelt where the density and thus tsetse challenge could be expected to be lower. The average prevalence of trypanosome infections in the tsetse-free study area was comparable to the one observed by Abebe \& Jobre (1996) in the Gojjam and Gonder highlands. 
Longitudinal studies conducted in the tsetse-infested Ghibe Valley (south-west Ethiopia) have shown that the incidence of trypanosome infections in cattle is highest during the dry season months of October to February, coinciding with the period of higher density of tsetse (Leak, Mulatu, Authie, D' leteren, Peregrine, Rowlands \& Trail 1993). In our study sites, the prevalence of trypanosome infections increased substantially during the long rainy season (June to October) and remained high during the early dry season (November). Outbreaks of acute T. vivax in Ethiopian cattle have been attributed to increased rainfall (Roeder, Scott \& Pegram 1984). D'Amico, Gouteux, Le Gall \& Cuisance (1996) demonstrated a high level of interaction between cattle and biting flies during the rainy season. The correlation between the prevalence of trypanosome infections and the IAA of biting flies also suggests a close link between trypanosomosis challenge and the number of biting flies. The relative epidemiological importance of the various species of biting flies present in the study area will be the subject of another study.

The majority of the trypanosome infections in both study areas were due to $T$. vivax. This high proportion of $T$. vivax infections is in accordance with observations made in other tsetse-free areas of Ethiopia (Roeder et al. 1984; Abebe \& Jobre 1996) and elsewhere (Jones \& Davila 2001). The high proportion of $T$. vivax infections in the tsetse-infested area contrasts sharply with trypanosome species prevalence data from other tsetse-infested regions of Ethiopia where $T$. congolense is the most prevalent trypanosome species in cattle (Leak et al. 1993; Abebe \& Jobre 1996). The high proportion of $T$. vivax infections in cattle sampled in our tsetse-infested areas is attributed to the location of the study sites which are situated on the edge of the tsetse-belt.

Ecological conditions for tsetse on the edge of a flybelt are usually less favourable resulting in a high mortality rate of tsetses and favouring the transmission of trypanosome species with a short developmental cycle such as $T$. vivax. Furthermore, the role of mechanical transmission of $T$. vivax in such areas cannot be underestimated. Similar conclusions were drawn by Kidanemariam et al. (2002) who conducted surveys along the edge of the tsetse-belt in southern Ethiopia. Although it has been shown that $T$. congolense and $T$. brucei can be transmitted mechanically, the transmission rate is usually low (Mihok, Maramba, Munyoki \& Kagoiya 1995). Hence, the $T$. congolense cases detected in the tsetse-free study area are attributed to cattle that were imported from the tsetse-infested into the tsetse-free area rather than mechanical transmission of this trypanosome species.

The presence of trypanosome infections resulted in a significant decline in PCV and body condition score. Other factors such as malnutrition or other diseases may also affect the PCV and body condition. However, it is unlikely that the impact of those additional factors differs greatly between the parasitologically positive and negative animals. Hence, relative comparisons between the PCV and body conditions score of parasitological positive and negative animals can be made. From the present study it can thus be concluded that trypanosomosis is an important disease and a potential threat in affecting the health and productivity of cattle in the economically important Amhara Region of north-west Ethiopia.

\section{ACKNOWLEDGEMENTS}

The authors acknowledge Prof. Dr Getachew Abebe of the Addis Abeba University, Faculty of Veterinary Medicine for his field supervision and assistance. The work presented in this paper was funded by the Ethiopian Agricultural Research Organisation and the Amhara Regional Agricultural Institute and Bureau of Agriculture of the Region. All staff of the Genetics Laboratory of the University Putra Malaysia and, in particular, Dr P. Kalaiselvi are thanked for their assistance. The Bahir Dar Regional Veterinary Laboratory staff and Drs Solomon, Ato Habtamu and Ato Sahile are thanked for their assistance.

\section{REFERENCES}

ABEBE, G. \& JOBRE, Y. 1996. Trypanosomosis: a threat to cattle production in Ethiopia. Revue de Médecine Vétérinaire, 147:897-902.

BOPED (2000). Amhara Regional State Bureau of Planning and Economic Development, Annual Report 2000.

BRIGHTWELL, R., DRANSFIELD, R.D., KYORKU, C., GOLDER, T.K., TARIMO, S.A. \& MUNGA, D. 1987. A new trap for Glossina pallidipes. Tropical Pest Management, 33:51-159.

CHALLIER, A., EYRAUD, M., LAFAYE, A. \& LAVEISSIÈRE, C. 1977. Amélioration du rendement du piège biconique pour glossines par emploi d'une cone inferieur blue. Cahier ORSTOM Série Entomologie Médicale et Parasitologie, 15: 283-286.

D'AMICO, F., GOUTEUX, J.P., LE GALL, F. \& CUISANCE, D. 1996. Are stable flies (Diptera: Stomoxynae) vectors of Trypanosoma vivax in the Central African Republic? Veterinary Research, 27:161-170.

JONES, T.W. \& DAVILA, A.M.R. 2001. Trypanosoma vivax-out of Africa. Trends in Parasitology, 17:99-101.

KIDANEMARIAM, A., HADGU, K. \& SAHLE, M. 2002. Parasitological prevalence of bovine trypanosomosis in Kindo 
Koisha district, Wollaita zone, south Ethiopia. Onderstepoort Journal of Veterinary Research, 69:107-113.

LANGRIDGE, W. 1976. Tsetse and trypanosomosis survey of Ethiopia. UK, Ministry of Overseas Department.

LEAK, S.G.A., MULATU, W., AUTHIE, E., D'IETEREN, G.D.M., PEREGRINE, A.S., ROWLANDS, G.J. \& TRAIL, J.C.M. 1993. Epidemiology of bovine trypanosomosis in the Ghibe valley, southwest Ethiopia 1. Tsetse challenge and its relationship to trypanosome prevalence in cattle. Acta Tropica, 53:121-134.

MIHOK, S., MARAMBA, O., MUNYOKI, E. \& KAGOIYA, J. 1995. Mechanical transmission of Trypanosoma spp. by African Stomoxyinae (Diptera: Muscidae). Tropical Medicine and Parasitology, 46:103-105.

NICHOLSON, J.M. \& BUTTERWORTH, M.H. 1986. A guide to condition scoring of zebu cattle. Addis Abeba: ILCA.
PARIS, J., MURRAY, M. \& MCODIMBA, F. 1982. A comparative evaluation of the parasitological techniques currently available for the diagnosis of African trypanosomosis in cattle. Acta Tropica, 39:307-316.

PUTT, S.P.M., SHAW, A.P.M., WOODS, A.J., TYLER, L. \& JAMES, A.D. 1988. Veterinary epidemiology and economics in Africa. Manual for use in the design and appraisal of livestock health policy. Addis Abeba: ILCA.

ROEDER, P.L., SCOTT, J.M. \& PEGRAM, R.G. 1984. Acute Trypanosoma vivax infection of Ethiopian cattle in the apparent absence of tsetse. Tropical Animal Health and Production, 16:141-147.

SLINGENBERGH, J. 1992. Tsetse control and agricultural development in Ethiopia. World Animal Review, 70-71:30- 36. 